\title{
Early Onset Parkinson's Disease in a family of Moroccan origin caused by a p.A217D mutation in PINK1: a case report
}

\author{
Brendan P. Norman ${ }^{1}$, Steven J. Lubbe ${ }^{2}$, Manuela Tan ${ }^{1}$, Naomi Warren ${ }^{1}$ and Huw R. Morris ${ }^{1 *}$ (D)
}

\begin{abstract}
Background: Bi-allelic mutations in the genes Parkin (PARK2), PINK1 (PARK6) and DJ-1 (PARK7) are established causes of autosomal recessive early-onset Parkinson's Disease (EOPD). PINK1 mutations are the second commonest cause of EOPD. Specific mutations may be relatively common in certain populations because of a founder effect. Homozygous p.A217D PINK1 mutations were previously shown to cause EOPD in a large Sudanese kindred.

Case presentation: Here we report the segregation of homozygous PINK1 p.A217D mutations in a family originating in Morocco with a history of parental consanguinity. From the clinical information available for the index case, the phenotype of mild, slowly-progressive Parkinsonism is consistent with previous reports of p.A217D disease and of PINK1 disease phenotype more generally. The reported features of early prominent lower-limb symptoms and gait disturbance with asymmetrical onset are more frequent among PINK1 disease cases.

Conclusions: Together, reports of p.A217D in families of Moroccan and Sudanese origin suggest that p.A217D is a North African mutation due to a founder effect. Wider genetic analyses of EOPD in North Africa would be useful to estimate the prevalence of Parkinsonism caused by PINK1 p.A217D. In the absence of bi-allelic Parkin mutations, PINK1 mutations should be considered in cases with evidence of autosomal recessive inheritance of EOPD and presentation of atypical features such as early lower-limb symptoms and gait disturbance with asymmetrical onset, which appear to be common in Mendelian EOPD.
\end{abstract}

Keywords: Early Onset Parkinson's Disease, PINK1 p.A217D

\section{Background}

Parkinson's Disease (PD) is the second commonest neurodegenerative disease, affecting approximately $1 \%$ of people over 50 years of age [1]. PD is caused by progressive selective death of dopaminergic neurons of the substantia nigra pars compacta [2].

Although most PD is sporadic, the discovery of genetic variants linked with $\mathrm{PD}$ in rare families with multiple affected members has elucidated some of the pathogenic mechanisms underlying neurodegeneration. In early-onset Parkinson's Disease (EOPD), genetic factors are probably more prominent, as there is a consistently stronger effect of familial aggregation compared to typical late onset PD [3]. Increased disease risk for siblings of people affected by

\footnotetext{
* Correspondence: h.morris@ucl.ac.uk

${ }^{1}$ Department of Clinical Neuroscience, Institute of Neurology, University

College London, London, UK

Full list of author information is available at the end of the article
}

EOPD as compared to parents is consistent with autosomal recessive disease.

Mutations in PARK2 (Parkin), PARK6 (PINK1) and PARK7 (DJ-1) cause autosomal recessive EOPD. Parkin point mutations and deletions are the commonest genetic cause of EOPD, with worldwide prevalence of $8.6 \%$ in EOPD. PINK1 mutations have intermediate prevalence of $3.7 \%$, while $D J-1$ mutations are rarer, accounting for $0.4 \%$ of EOPD [4]. Causal mutations in Parkin, PINK1 and DJ-1 implicate disrupted mitochondrial homeostasis as a key pathophysiologic event in EOPD. Amongst other diverse functions, Parkin and PINK1 have a well-established interactive role in mitochondrial quality control [5-7].

Over 40 point mutations and rarer large deletions in PINK1 are reported to be pathogenic when inherited as bi-allelic mutations in EOPD cases [8]. PINK1 mutation prevalence varies with ethnicity, with greater prevalence in Asian cases (13.5\% among EOPD cases) compared to 
white or Latin American cases ( $<1 \%$ among EOPD cases) [4]. Despite the large number of different PINK1 mutations reported, individually each is rare [9]. The pathogenicity of rare mutations shown to segregate with EOPD in just one family is less certain. Identification of families showing segregation of the same bi-allelic variant increases confidence in its pathogenicity. Here we report a new family with PINK1 disease.

\section{Case presentation \\ Patients}

The patients were of French North African descent, originating in Morocco. The siblings were born in France. The kindred comprises two generations, of which two secondgeneration family members had a Parkinsonian disorder (Fig. 1a). One second-generation family member died in 2006 in a road traffic accident. The parents were first cousins.

DNA was available for four family members: two affected (MF_1 [index] and MF_3) and one unaffected (MF_2).

\section{Clinical history}

Clinical information was only available for the index case (MF_1), who developed symptoms in 2003, age 29 years with tremor of the left hand, micrographia, slowness in walking and a sensation of heavy legs. In 2005, symptoms progressed, with a tendency to drag the right leg. MF_1 was first examined in 2009, age 34 and had bilateral bradykinesia, rigidity, postural and rest tremor. Tremor and rigidity were noticeably worse on the left. Additional features included mild facial hypomimia, lower-limb hyperreflexia and eye movement 'catch-up' saccades without noticeable slowness of eye movements in the vertical plane. A DaTscan showed reduced dopamine receptor binding in the putamen bilaterally consistent with nigrostriatal cell loss. There were no signs of cognitive nor neuropsychiatric disturbance, and tests for copper abnormalities, neuroferritinopathy and adjusted calcium, liver and thyroid function were normal. An MRI brain scan revealed no significant abnormality. MF_1 reported three falls within a twelve month period but was independent in activities of daily living. Symptoms were mild in the morning with deterioration as the day progressed. MF_1 was prescribed rasagiline, with some improvement in gait.

Six years after symptom onset a formal detailed assessment was carried out. Motor assessment: MF_1 completed parts II ('motor aspects of experiences of daily living') and III ('motor examination') of the Movement Disorder Society revised Unified Parkinson's Disease Rating Scale (MDS-UPDRS; [10]) and recorded total scores of 7/52 and 38/429 respectively. Notable findings from the part III motor examination were increased bradykinesia and rigidity for the lower body compared with upper body, with greater impairment on the left side. Hoehn and
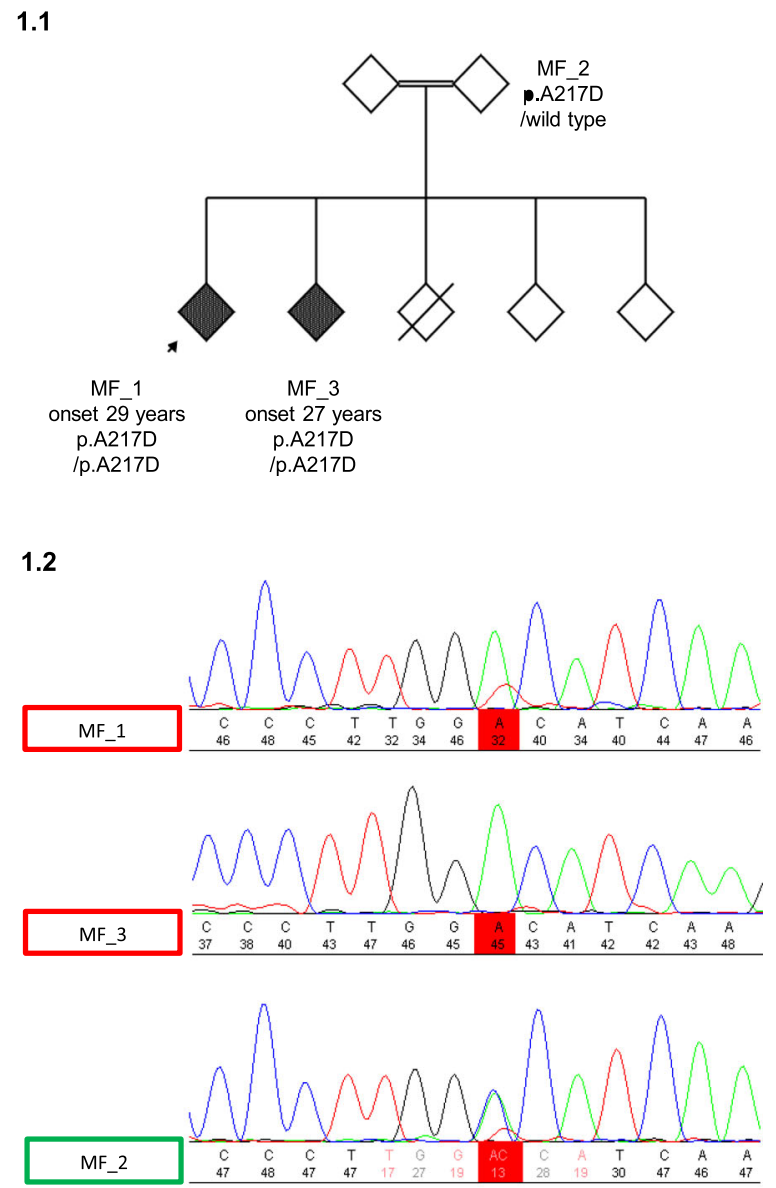

1.3

Ensemble Gene Identification Homo sapiens ENST00000289840 Pan troglodyles ENSPTRT0000000572 Macaca fascicularis gil5451340, dbjBAB64474. Rattus norvegicus ENSRNOTO0000020820 Mus musculus ENSMUST00000030536 Danio rerio ENSDART00000035872
Takifugu rubripes SINFRUT00000129020 Takifugu rubripes SINFRUT00000129020 Drosophila melanogaster CG4523-AA
Caenorhabditis elegans EEED8.9

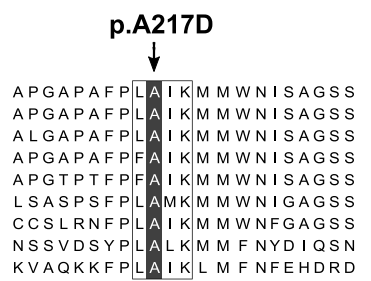

Fig. 1 a Genetic pedigree of the family, with EOPD status indicated by shaded diamonds. Arrow indicates index case. $\mathbf{b}$ Chromatographs from sequencing with the c.650 position of PINK1 exon 2 highlighted. Traces for affected family members MF_1 (index case) and MF_3 show homozygous C > A transversions, while that of the 'carrier' MF_2 shows a heterozygous transversion. c Multiple alignments of the PINK1 protein in clustal format. Box indicates highly conserved ATPase orientation site. Shading indicates the position of the P.A217D mutation

Yahr stage was 2; classified as 'bilateral impairment without impairment of balance' [11].

Neuropsychological assessment: MF_1's scores were both within the defined 'normal' range for both the Montreal Cognitive Assessment (MoCA; [12]), Mini-Mental State Examination (MMSE; [13]) and Geriatric Depression Scale-15 [14]. 
Non-Motor Assessment: Scores for the Epworth Sleepiness Scale [15] and overall sleep quality (Pittsburgh Sleep Quality Index [16]) were normal. Responses to the NonMotor Symptoms Questionnaire (NMS-Quest; [17]) did not indicate any significant abnormality of sleep, sphincter or other autonomic function and there was no significant postural drop in blood pressure.

In 2011 MF_1 reported making some typing mistakes at work due to bradykinesia and reported some back and shoulder pain. In 2012, symptoms had progressed, with a gradual increase in slowness of movement and rigidity. Tremor was mild, but speech had deteriorated, with more noticeable dysarthrophonia. Symptoms responded well to ropinirole, which MF_1 had been taking for around six months at the time of examination. In 2012, MF_1 was continuing to work full-time and walk to work every morning. MF_1 was not taking L-DOPA.

\section{Genetic analysis}

Genetic analysis of the family was approved under the Research Ethics Committee for Wales (Wales REC; 14/ WA/1179; Clinical Neurological Disease Bio-bank and Neurogenetics Research Study 2 (CANDAS2)). Diagnostic testing was performed for Parkin and LRRK2 only. Whole exome sequencing was sought on the index case to eliminate other established recessive mutations. Briefly, sample libraries were prepared using Illumina capture kits with paired-end sequencing performed on the Illumina HiSeq2000. All reads were aligned using BWA against the UCSC hg19 reference genome [18]. Variant calling and quality-based filtering were done using GATK [19]. ANNOVAR [20] was used to annotate variants. Sanger sequencing was performed to validate any identified variants.

Initial genetic tests of the index case did not find a Parkin or LRRK2 mutation. Subsequent whole exome sequencing confirmed absence of Parkin and LRRK2 mutations, but revealed a homozygous p.A217D mutation in PINK1 (rs74315360).

Sanger sequencing confirmed the p.A217D mutation (Fig. 1b). Cases show homozygous $\mathrm{C}>\mathrm{A}$ transversions at c.650 (NM_032409.2:c.650C > A), resulting in an alanine to aspartic acid substitution at position 217 of PINK1. The unaffected family member analysed shows a heterozygous transversion, identifying them as a carrier of the p.A217D mutation. We have therefore identified the genetic cause of this family's EOPD.

\section{Discussion and conclusions}

Although PINK1 mutations are an established cause of EOPD, to our knowledge this is the second report of the PINK1 p.A217D mutation. p.A217D is a missense mutation altering a highly-conserved amino acid of the kinase domain in the ATPase orientation site of PINK1 (Fig. 1c).
p.A217D was predicted to be damaging by all six in silico prediction tools from the genetic analysis [21-26]. Homozygous PINK1 p.A217D mutations were previously found to segregate with EOPD in a large Sudanese kindred, in addition to its absence from 394 sequenced control chromosomes [27]. The rarity of this mutation is confirmed by its absence from the ExAC database (http://exac.broadinstitute.org), comprising approximately 60,000 individuals, of which about 5000 are African or AfricanAmerican, likely to be of largely sub-Saharan origin [28]. The finding that the homozygous p.A217D mutation segregates with PD in this family of Moroccan origin adds weight to its pathogenic status.

Similarities between the clinical phenotype of the index case here and that previously reported for homozygous p.A217D PD cases are classical Parkinsonism and a relatively benign disease course. The most prominent difference is the later age at onset (AAO) of the cases here (27-29 years) compared to the previous p.A217D cases' mean AAO of 12.6 years (range: 9-14 years).

The clinical phenotype reported here is consistent with the documented PINK1 EOPD phenotype of relatively mild, slowly progressive classical Parkinsonism [29-32]. An interesting feature of the index case's disease here is early, asymmetric gait disturbance. Lower limb symptoms and particularly gait disturbance are typically late features of idiopathic PD and usually accompanied by motor and cognitive decline [33] but they appear to be prominent early features of PINK1 disease [27, 34-36]. The index case showed prominent lower limb hyper-reflexia upon examination; hyper-reflexia has been reported to be more frequent in PINK1 cases than cases without PINK1 mutations or cases with Parkin mutations [32].

The literature on PINK1 EOPD suggests increased prevalence of some non-motor PD symptoms compared with idiopathic PD. These include mild cognitive impairment [37-41] and psychiatric abnormalities such as affective and behavioural disorders [34-36, 42, 43]. However prominent autonomic features, common in Lewy body PD such as REM sleep behaviour disorder, constipation and urinary symptoms are usually absent in Parkin and PINK1 disease. The index case in this study did not have significant cognitive, neuro-psychiatric or autonomic clinical features. In summary, EOPD cases with homozygous PINK1 p.A217D mutations reported here $a$ ) share most clinical features with previously reported p.A217D cases except with older $\mathrm{AAO}, b$ ) are consistent with the previously reported PINK1 EOPD phenotype more generally but with earlier AAO and without cognitive or neuropsychiatric disturbance, and together with other reports support the presence of features that add to a unique clinical Parkinsonian phenotype associated with PINK1 mutations.

As the second report of p.A217D in cases originating in North Africa, p.A217D is probably a North African 
PINK1 mutation. Specific PINK1 mutations have relatively high frequency in some populations. For example the p.L347P mutation has a carrier frequency of $8 \%$ in the Philippines, indicating a founder effect [44]. Genetic analysis is not widely performed in North Africa, so further patients and kindreds may be found with PINK1 p.A217D disease.

In conclusion, we report the second occurrence of the PINK1 p.A217D mutation in a family affected by EOPD. Our result adds weight to the pathogenic status of this mutation and expands knowledge of the geographic diversity of p.A217D mutations to the Moroccan sub-region of North Africa.

\section{Abbreviations}

AAO: Age at onset; EOPD: Early-onset Parkinson's Disease; PD: Parkinson's Disease

\section{Acknowledgements}

The authors would like to acknowledge the following:

The family for donating DNA samples and consenting to the genetic analyses undertaken. The funding sources: Parkinson's UK and Medical Research Council. We are grateful to the ICICLE-PD study group for sharing their study data.

\section{Funding}

This work was supported by Parkinson's UK (grants 8047, J-0804) and the Medical Research Council (G0700943, G1100643).

\section{Availability of data and materials}

All data generated or analysed during this study are included in this published article.

\begin{abstract}
Authors' contributions
NW referred the case family for genetic analysis. BN and SL performed Sanger Sequencing on DNA obtained from cases for validation of the PINK1 p.A217D mutation. MT was responsible for accessing clinical information relating to the index case and obtaining written consent to publish these details. BN prepared the first draft of the manuscript and was responsible for preparation of subsequent revisions. NW, SL and HRM provided comments on earlier drafts of the manuscript. All authors read and approved the final manuscript.
\end{abstract}

\section{Ethics approval and consent to participate}

Genetic analysis of the family was approved under the Research Ethics Committee for Wales (Wales REC; 14/WA/1179; Clinical Neurological Disease Bio-bank and Neurogenetics Research Study 2 (CANDAS2)).

\section{Consent for publication}

All cases for whom clinical histories were available provided written consent to publish these details in the manuscript.

\section{Competing interests}

Financial Disclosures for previous 12 months: H.R.M. reports grants from Welsh Assembly Government, personal fees from Teva Pharmaceutical Industries, personal fees from Abbvie, personal fees from Teva, personal fees from University College Birmingham, personal fees from Boerhinger-Ingelheim, personal fees from GlaxoSmithKline, non-financial support from Teva Pharmaceutical Industries, grants from Ipsen Fund, non-financial support from Medtronic, grants from Motor Neuron Disease Association (MNDA), grants from Progressive Supranuclear Palsy Association, grants from CBD Solutions, grants from the Drake Foundation, outside the submitted work; In addition, H.R.M. has a patent - H.R.M is a co-applicant on a patent application related to C9ORF72 - Method for diagnosing a neurodegenerative disease (PCT/GB2012/052140) pending.

All other authors declare that they have no competing interests.

\section{Publisher's Note}

Springer Nature remains neutral with regard to jurisdictional claims in published maps and institutional affiliations.

\section{Author details}

${ }^{1}$ Department of Clinical Neuroscience, Institute of Neurology, University College London, London, UK. ${ }^{2}$ Ken and Ruth Davee Department of Neurology, Northwestern University Feinberg School of Medicine, Chicago, USA.

Received: 3 March 2017 Accepted: 31 July 2017

Published online: 08 August 2017

\section{References}

1. Tanner CM, Goldman SM. Epidemiology of Parkinson's disease. Neurol Clin. 1996:14(2):317-35.

2. Cornford ME, Chang L, Miller BL. The neuropathology of parkinsonism: an overview. Brain Cogn. 1995:28(3):321-41.

3. Thacker EL, Ascherio A. Familial aggregation of Parkinson's disease: a metaanalysis. Mov Disord. 2008;23(8):1174-83.

4. Kilarski LL, Pearson JP, Newsway V, Majounie E, Knipe MDW, Misbahuddin A, et al. Systematic review and UK-based study of PARK2 (parkin), PINK1, PARK7 (DJ-1) and LRRK2 in early-onset Parkinson's disease. Mov Disord. 2012;27(12):1522-9.

5. Scarffe LA, Stevens DA, Dawson VL, Dawson TM. Parkin and PINK1: much more than mitophagy. Trends Neurosci. 2014;37(6):315-24.

6. Pickrell AM, Youle RJ. The Roles of PINK1, Parkin, and Mitochondrial Fidelity in Parkinson's Disease. Neuron. 2015;85(2):257-73.

7. Arena $G$, Valente EM. PINK1 in the limelight: multiple functions of an eclectic protein in human health and disease. J Pathol. 2017;241(2):251-63.

8. Lesage S, Brice A. Parkinson's disease: from monogenic forms to genetic susceptibility factors. Hum Mol Genet. 2009;18(R1):R48-59.

9. Puschmann A. Monogenic Parkinson's disease and parkinsonism: clinical phenotypes and frequencies of known mutations. Parkinsonism Relat Disord. 2013;19(4):407-15.

10. Goetz CG, Tilley BC, Shaftman SR, Stebbins GT, Fahn S, Martinez-Martin P, et al. Movement Disorder Society-sponsored revision of the Unified Parkinson's Disease Rating Scale (MDS-UPDRS): scale presentation and clinimetric testing results. Mov Disord. 2008;23(15):2129-70.

11. Hoehn MM, Yahr MD. Parkinsonism: onset, progression and mortality. Neurology. 1967;17(5):427-42.

12. Nasreddine ZS, Phillips NA, Bédirian V, Charbonneau S, Whitehead V, Collin I, et al. The Montreal Cognitive Assessment, MoCA: a brief screening tool for mild cognitive impairment. J Am Geriatr Soc. 2005;53(4):695-9.

13. Folstein MF, Folstein SE, McHugh PR. "Mini-mental state". A practical method for grading the cognitive state of patients for the clinician. J Psychiatr Res. 1975 Nov;12(3):189-98.

14. Yesavage JA, Brink TL, Rose TL, Lum O, Huang V, Adey M, et al. Development and validation of a geriatric depression screening scale: a preliminary report. J Psychiatr Res. 1982;17(1):37-49.

15. Johns MW. A new method for measuring daytime sleepiness: the Epworth sleepiness scale. Sleep. 1991;14(6):540-5

16. Buysse DJ, Reynolds CF, Monk TH, Berman SR, Kupfer DJ. The Pittsburgh Sleep Quality Index: a new instrument for psychiatric practice and research. Psychiatry Res. 1989:28(2):193-213.

17. Chaudhuri KR, Martinez-Martin P, Schapira AHV, Stocchi F, Sethi K, Odin P, et al. International multicenter pilot study of the first comprehensive selfcompleted nonmotor symptoms questionnaire for Parkinson's disease: the NMSQuest study. Mov Disord. 2006;21(7):916-23.

18. Li H, Durbin R. Fast and accurate short read alignment with Burrows-Wheeler transform. Bioinformatics. 2009;25(14):1754-60.

19. McKenna A, Hanna M, Banks E, Sivachenko A, Cibulskis K, Kernytsky A, et al. The Genome Analysis Toolkit: a MapReduce framework for analyzing nextgeneration DNA sequencing data. Genome Res. 2010;20(9):1297-303.

20. Wang K, Li M, Hakonarson H. ANNOVAR: functional annotation of genetic variants from high-throughput sequencing data. Nucleic Acids Res. 2010;38(16):e164

21. Ng PC, Henikoff S. Predicting deleterious amino acid substitutions. Genome Res. 2001;11(5):863-74

22. Pollard KS, Hubisz MJ, Rosenbloom KR, Siepel A. Detection of nonneutral substitution rates on mammalian phylogenies. Genome Res. 2010;20(1):110-21. 
23. Adzhubei I a, Schmidt S, Peshkin L, Ramensky VE, Gerasimova A, Bork P, et al. A method and server for predicting damaging missense mutations. Nat Methods. 2010;7(4):248-9.

24. Chun S, Fay JC. Identification of deleterious mutations within three human genomes. Genome Res. 2009;19(9):1553-61.

25. Schwarz JM, Rödelsperger C, Schuelke M, Seelow D. MutationTaster evaluates disease-causing potential of sequence alterations. Nat Methods. 2010;7(8):575-6

26. Davydov EV, Goode DL, Sirota M, Cooper GM, Sidow A, Batzoglou S. Identifying a high fraction of the human genome to be under selective constraint using GERP++. PLoS Comput Biol. 2010;6(12):e1001025.

27. Leutenegger A-L, Salih MAM, Ibáñez P, Mukhtar MM, Lesage S, Arabi A, et al. Juvenile-onset Parkinsonism as a result of the first mutation in the adenosine triphosphate orientation domain of PINK1. Arch Neurol. 2006:63(9):1257-61.

28. Lek M, Karczewski KJ, Minikel EV, Samocha KE, Banks E, Fennell T, et al. Analysis of protein-coding genetic variation in 60,706 humans. Nature. 2016;536(7616):285-91.

29. Bonifati V, Rohé CF, Breedveld GJ, Fabrizio E, De Mari M, Tassorelli C, et al. Early-onset parkinsonism associated with PINK1 mutations: frequency, genotypes, and phenotypes. Neurology. 2005;65(1):87-95.

30. Valente EM, Bentivoglio AR, Dixon PH, Ferraris A, lalongo T, Frontali $M$, et al. Localization of a novel locus for autosomal recessive early-onset parkinsonism, PARK6, on human chromosome 1p35-p36. Am J Hum Genet. 2001;68(4):895-900.

31. Hatano $Y$, Sato $K$, Elibol B, Yoshino H, Yamamura $Y$, Bonifati V, et al. PARK6linked autosomal recessive early-onset parkinsonism in Asian populations. Neurology. 2004;63(8):1482-5

32. Ibáñez $P$, Lesage $S$, Lohmann $E$, Thobois $S$, De Michele $G$, Borg M, et al. Mutational analysis of the PINK1 gene in early-onset parkinsonism in Europe and North Africa. Brain. 2006;129(3):686-94.

33. Burn DJ, Rowan EN, Allan LM, Molloy S, O'Brien JT, McKeith IG. Motor subtype and cognitive decline in Parkinson's disease, Parkinson's disease with dementia, and dementia with Lewy bodies. J Neurol Neurosurg Psychiatry. 2006;77(5):585-9.

34. Samaranch L, Lorenzo-Betancor O, Arbelo JM, Ferrer I, Lorenzo E, Irigoyen J, et al. PINK1-linked parkinsonism is associated with Lewy body pathology. Brain. 2010;133(4):1128-42

35. Ephraty L, Porat O, Israeli D, Cohen OS, Tunkel O, Yael S, et al. Neuropsychiatric and cognitive features in autosomal-recessive early parkinsonism due to PINK1 mutations. Mov Disord. 2007;22(4):566-9.

36. Marongiu R, Ferraris A, lalongo T, Michiorri S, Soleti F, Ferrari F, et al. PINK1 heterozygous rare variants: prevalence, significance and phenotypic spectrum. Hum Mutat. 2008;29(4):565.

37. Fiorio M, Valente EM, Gambarin M, Bentivoglio AR, lalongo T, Albanese A, et al. Subclinical sensory abnormalities in unaffected PINK1 heterozygotes. J Neurol. 2008;255(9):1372-7.

38. Ferraris A, lalongo T, Passali GC, Pellecchia MT, Brusa L, Laruffa M, et al. Olfactory dysfunction in Parkinsonism caused by PINK1 mutations. Mov Disord. 2009;24(16):2350-7.

39. Kertelge L, Brüggemann N, Schmidt A, Tadic V, Wisse C, Dankert S, et al. Impaired sense of smell and color discrimination in monogenic and idiopathic Parkinson's disease. Mov Disord. 2010;25(15):2665-9.

40. Eggers C, Schmidt A, Hagenah J, Brüggemann N, Klein JC, Tadic V, et al. Progression of subtle motor signs in PINK1 mutation carriers with mild dopaminergic deficit. Neurology. 2010;74(22):1798-805.

41. Ricciardi L, Petrucci S, Guidubaldi A, lalongo T, Serra L, Ferraris A, et al. Phenotypic variability of PINK1 expression: 12 Years' clinical follow-up of two Italian families. Mov Disord. 2014;29(12):1561-6.

42. Reetz K, Lencer R, Steinlechner S, Gaser C, Hagenah J, Büchel C, et al. Limbic and frontal cortical degeneration is associated with psychiatric symptoms in PINK1 mutation carriers. Biol Psychiatry. 2008;64(3):241-7.

43. Steinlechner S, Stahlberg J, Völkel B, Djarmati A, Hagenah J, Hiller A, et al. Co-occurrence of affective and schizophrenia spectrum disorders with PINK1 mutations. J Neurol Neurosurg Psychiatry. 2007;78(5):532-5.

44. Rogaeva E, Johnson J, Lang AE, Gulick C, Gwinn-Hardy K, Kawarai T, et al. Analysis of the PINK1 gene in a large cohort of cases with Parkinson disease. Arch Neurol. 2004;61(12):1898-904.

\section{Submit your next manuscript to BioMed Central and we will help you at every step:}

- We accept pre-submission inquiries

- Our selector tool helps you to find the most relevant journal

- We provide round the clock customer support

- Convenient online submission

- Thorough peer review

- Inclusion in PubMed and all major indexing services

- Maximum visibility for your research

Submit your manuscript at www.biomedcentral.com/submit
C) Biomed Central 